\title{
ARROZ COMERCIALIZADO NA REGIÃO SUL DO BRASIL: ASPECTOS MICOTOXICOLÓGICOS E MICROSCÓPICOS ${ }^{1}$
}

\author{
Itaciara Larroza NUNES ${ }^{2}$, Glênio MAGAGNIN², Telma Elita BERTOLIN², Eliana Badiale FURLONG ${ }^{2, *}$
}

\section{RESUMO}

Foi realizado um levantamento de características micotoxicológicas e microscópicas em arroz destinado ao consumo humano, comercializado nas cidades de Pelotas e Rio Grande, RS. As amostras, arroz integral [16], arroz parboilizado [16] e arroz branco polido [24] foram coletadas em supermercados, no periodo de maio a setembro de 2000 . A avaliação de ocorrência de aflatoxinas $B_{1}$, $B_{2}$, $G_{1}$, $G_{2}$, ocratoxina A, zearalenona, desoxinivalenol e toxina T-2 foi realizada pela técnica de cromatografia de camada delgada (CCD). As duas últimas toxinas foram avaliadas também pela técnica de cromatografia gasosa (CG). A micoflora foi determinada através de plaqueamento em superficie em Ágar Batata Dextrose Acidificado, com incubação a $25^{\circ} \mathrm{C}$ por 5 dias. As colônias mais freqüentes foram identificadas através da técnica de microcultivo. Dentre as amostras analisadas, duas apresentaram contaminação por ocratoxina A (104 e 128 4 g. Kg ${ }^{-1}$ ), três por zearalenona $\left(559,1117\right.$ e $\left.1955 \mu \mathrm{g} \cdot \mathrm{Kg}^{-1}\right)$, sendo uma co-contaminação com a primeira. Uma das amostras estava contaminada

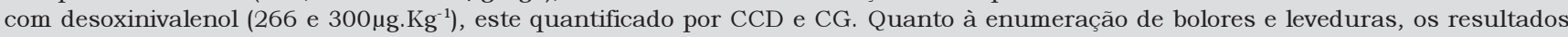
mostraram que $3,6 \%$ das amostras apresentaram valores superiores a $10{ }^{4}$ UFC.g ${ }^{-1}$ e $11 \%$ valores próximos deste. Sujidades microscópicas, acima dos limites da legislação $(0,25 \%)$, foi detectada em uma amostra de arroz integral.

Palavras-chave: arroz; micotoxinas; micoflora

\section{SUMMARY}

RICE COMERCIALIZED IN SOUTHERN BRAZIL: MICOTOXICOLOGICAL AND MICROSCOPIC ASPECTS. A survey was carried out of the micotoxicological and microscopic characteristics of rice comercialized in Pelotas and Rio Grande, RS, Brazil. Samples of whole [16], parboilized [16] and polished white rice [24] were collected in supermarkets, from may until september 2000.The occurrence of aflatoxin $\mathrm{B}_{1}, \mathrm{~B}_{2}, \mathrm{G}_{1}, \mathrm{G}_{2}$ ochratoxin A, zearelenone, desoxynivalenol and T2 toxin was evaluated using thin layer chromatographic technique (TLC). The last two toxins were also evaluated by gas chromatography (CG). Mycoflora was determined using a surface Potato Dextrose Acid Agar, incubated for 5 days at $25^{\circ} \mathrm{C}$. The most frequent colonies were identified using the microcultive technique. The occurrence of microscopic dirt was realized in accordance with AOAC. Among the samples analyzed, 2 presented contamination by ochratoxin A (104 and $\left.128 \mu \mathrm{g} \cdot \mathrm{Kg}^{-1}\right)$ and three with zearalenone $\left(559,1117\right.$ and $\left.1955 \mu \mathrm{g} . \mathrm{Kg}^{-1}\right)$, one of wich was cause by co-contamination with the first. One sample was contamined with desoxynivalenol (266 e $\left.300 \mu \mathrm{g} . \mathrm{Kg}^{-1}\right)$, determined by TLC and GC. The results showed that $3.6 \%$ of the samples have levels above and $11 \%$ near $10^{4} \mathrm{CFU} / \mathrm{g}$. A brown rice sample was contaminated by microscopic dirt the above legal legislation $(0.25 \%)$.

Keywords: rice; micotoxin; mycoflora.

\section{1 - INTRODUÇÃO}

O arroz é um cereal que faz parte do hábito alimentar do brasileiro, o que se confirma pelo consumo per capita superior a $70 \mathrm{~kg} /$ habitante/ano, considerando suas diferentes formas. [1, 20]. A produção nacional concentra-se nos Estados da região Sul e o cultivo é feito principalmente sob a forma irrigada. Esta condição propicia a umidade necessária para a contaminação dos grãos por fungos, além disso o arroz é rico em carboidratos, substrato preferencial para o desenvolvimento destes microrganismos [7].

Quando grãos de cereais são colonizados por fungos pode haver o risco de contaminação por micotoxinas, produtos do metabolismo secundário formados em condições de estresse, desbalanço de nutrientes e condições ambientais propicias. Além de diversos efeitos tóxicos agudos estas toxinas podem acarretar problemas crônicos graves como imunossupressão e carcinogenicidade $[9,13]$.

Os gêneros fúngicos mais freqüentemente associados à produção de micotoxinas em cereais são Aspergillus,

Recebido para publicação em 07/08/2001. Aceito para publicação em 06/01/2003 (000708).

2. Fundação Universidade Federal do Rio Grande - Depto de Quimica Rua Engenheiro Alfredo Huch, 475 - CEP 96201-900, Rio Grande, RS Email:dqmebf@super.furg.br

* A quem a correspondência deve ser enviada.
Penicillium e Fusarium. Ainda que o fungo possa ser inativado ou retirado durante o processamento e não estar presente no produto manufaturado, as toxinas podem permanecer viáveis, pois não são facilmente degradáveis [9, 14].

O fato de o arroz ser um alimento de consumo quase diário, pela maioria da população brasileira, torna importante o conhecimento dos niveis de contaminação fúngica e a identificação dos mesmos, para posterior avaliação das possiveis causas da contaminação, dos riscos à saúde do consumidor e possivelmente tomada de medidas efetivas, no sentido de garantir a segurança alimentar da população.

Assim, visando contribuir para a obtenção de dados sobre a qualidade do arroz consumido na região Sul do Rio Grande do Sul, os objetivos deste trabalho foram: avaliar a ocorrência de micotoxinas (aflatoxinas $\mathrm{B}_{1}, \mathrm{~B}_{2}$, $\mathrm{G}_{1}, \mathrm{G}_{2}$, ocratoxina A, zearalenona, desoxinivalenol e toxina T-2), a micoflora e sujidades microscópicas em diferentes tipos de arroz destinado ao consumo humano.

\section{2 - MATERIAL E MÉTODOS}

\section{1 - Amostragem}

A coleta de amostras realizou-se no período de maio a setembro de 2000 em duas redes de supermercados, 
nas cidades de Pelotas e Rio Grande, região Sul do Rio Grande do Sul. Foram coletadas as marcas mais consumidas na região, sendo: 6 de arroz polido e 4 de arroz integral e parboilizado. A quantidade amostrada correspondeu a $1 \%$ dos pacotes de $1 \mathrm{~kg}$ de cada marca existente na prateleira dos estabelecimentos, no momento da coleta, constituindo o lote de amostra bruta. De cada um destes lotes foi tomado aleatoriamente 0,5\%, que constituiu a amostra de laboratório.

Após as amostras de laboratório de cada marca foram homogeneizadas e trituradas em moinho de facas, até granulometria de $60-70$ mesh, e quarteados para a tomada da amostra analitica. Foram formadas para as determinações, realizadas em triplicatas, 24 de amostras de arroz branco polido, 16 de arroz integral e 16 lotes de arroz parboilizado, totalizando 56 amostras analiticas provenientes dos lotes formados nas coletas das diferentes marcas e períodos de tomada.

\section{2 - Triagem e quantificação das aflatoxinas, ocratoxina A, zearalenona, desoxinivalenol e toxina T2 por cromatografia de camada delgada}

O esquema para extração, purificação e quantificação de aflatoxinas, ocratoxina A e zearalenona, segundo o procedimento descrito por SOARES [18] aparece na Figura 1. Foram utilizadas placas prontas de silica gel G $60 \mathrm{com} 0,25 \mathrm{~mm}$ de espessura como fase estacionária. $\mathrm{O}$ sistema solvente utilizado para eluição destas toxinas foi tolueno : acetato de etila : ácido fórmico (5:3:1).

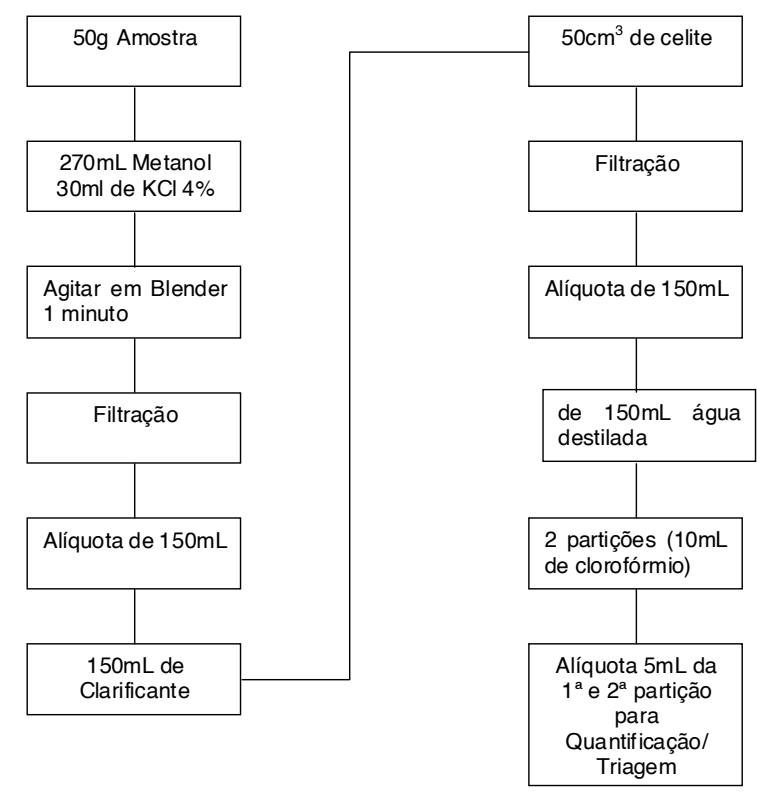

FIGURA 1. Esquema das etapas de extração e limpeza para triagem e quantificação de aflatoxinas, zearalenona e ocratoxina A em arroz por cromatografia de camada delgada.

Para determinação de desoxinivalenol e toxina T-2 foi empregado o método descrito por BARAJ [6]. Este constava de etapas semelhantes ao método de SOARES [18], acima esquematizado, até as partições onde se em- pregavam 2 lavagens suscessivas com $10 \mathrm{~mL}$ de cloreto de metileno. Os extratos da partição foram limpos em minicolunas de carvão ativo : alumina: celite $(0,7 \mathrm{~g}: 0,5 \mathrm{~g}$ $: 0,3 \mathrm{~g})$, empregando como eluente cloreto de metileno em quatro porções de $5 \mathrm{~mL}$. Após a eluição $10 \mathrm{~mL}$ do extrato foram evaporados em banho-maria a $50^{\circ} \mathrm{C}$, sob corrente de nitrogênio; ressuspensos em $200 \mathrm{~mL}$ de benzeno e cromagrafados usando a fase estacionária do caso anterior e como eluente tolueno : acetato de etila : ácido fórmico $(5: 4: 1)$. Nos dois casos foram usados procedimentos para confirmação das amostras suspeitas baseados em derivação química [6, 18].

A quantificação das amostras confirmadas foi realizada através de comparação visual com padrões de concentrações crescentes, sob luz ultravioleta de ondas longas e curtas. Para visualização dos tricotecenos as placas foram reveladas com solução de $\mathrm{H}_{2} \mathrm{SO}_{4}$ em etanol $50 \%$ e aquecimento $120^{\circ} \mathrm{C}$ por 10 minutos.

\section{3 - Determinação de tricotecenos por cromatogra- fia gasosa}

Os extratos das amostras, obtidos como o descrito no item anterior, foram derivadas em duplicatas com anidrido trifluoroacético(TFAA) e $\mathrm{NaHCO}_{3}$, adaptando o procedimento de SCHOLLENBERGER et al. [16]. O procedimento consistiu em adicionar cerca de $30 \mathrm{mg}$ de bicarbonato de sódio anidro e $300 \mu \mathrm{L}$ de TFAA ao residuo de padrão de tricoteceno ou extrato de amostra seco.

O frasco fechado foi agitado e levado ao banho-maria por 30 minutos a $80^{\circ} \mathrm{C}$ para a acetilação. Após atingir a temperatura ambiente e o derivado evaporado sob nitrogênio, o mesmo foi extraído com $500 \mu \mathrm{L}$ de tolueno sob agitação em banho - ultra - sônico. A solução resultante foi lavada duas vezes com $1000 \mu \mathrm{L}$ de água deionizada, duas vezes, foi adicionado 5 a $10 \mathrm{mg}$ de sulfato de sódio anidro, agitado em banho ultra-sônico por 10 segundos e levado ao congelador para a separação das fases.

Aliquotas de $400 \mu \mathrm{L}$ da fase orgânica foram evaporadas sob nitrogênio a temperatura ambiente. Ao resíduo seco foi adicionado o padrão interno (metil aracdato) e 100uL de hexano antes de injetar no cromatógrafo a gás.

A determinação quali e quantitativa dos tricotecenos DON e toxina T-2 foi realizada em um cromatógrafo a gás marca VARIAN, modelo STAR $3400 \mathrm{Cx}$, com injetor split/splitless (1078) e detector de ionização de chama, equipado com coluna de silica fundida com fase VA-WAX $(25 \mu \mathrm{m}$ de polietilenoglicol, $30 \mathrm{~m}$ de comprimento e $0,32 \mathrm{~mm}$ de diâmetro interno), acoplado ao Software Star Chromatography Workstation 4.51.

As condições cromatográficas empregadas para a injeção da amostra foram: temperatura do injetor $\left(250^{\circ} \mathrm{C}\right)$, tempo de abertura da válvula aos 0,5 minutos e vazão do gás de arraste (hidrogênio) $1 \mathrm{~mL} /$ minuto. A programação da coluna foi $100^{\circ} \mathrm{C} / 2 \mathrm{~min}$, aumentando $10^{\circ} \mathrm{C} /$ minuto até $180^{\circ} \mathrm{C}$, permanecendo 1 minuto e aumentando $15^{\circ} \mathrm{C} / \mathrm{mi}-$ nuto até $205^{\circ} \mathrm{C}$, permanecendo 5 minutos e aumentando $15^{\circ} \mathrm{C} /$ minuto até $220^{\circ} \mathrm{C}$, permanecendo 10 minutos. A temperatura utilizada no detector foi de $300^{\circ} \mathrm{C}$. 


\section{4 - Determinação da micoflora}

A enumeração de bolores e leveduras foi realizada através da técnica de plaqueamento em superficie de Agar Batata Dextrose Acidificado a uma temperatura de incubação de $25^{\circ} \mathrm{C}$ por 5 dias, conforme ABNT - MB- 2750 [17].

As colônias mais freqüentes foram identificadas pelas características macroscópicas das colônia e observação microscópica após preparo de microcultivos [14, 15].

\section{5 - Identificação de sujidades}

A identificação de sujidades presentes nas amostras foi realizada de acordo com o método de flutuação em heptano, para isolar sujidades leves e externas [3].

\section{3 - RESULTADOS E DISCUSSÃO}

\section{1 - Amostragem}

Tendo em vista o consumo diário do arroz o sistema de amostragem utilizado incluiu no estudo as marcas e os subgrupos de arroz mais consumidos na região estudada. Nortearam o número de marcas de cada subgrupo o consumo e a disponibilidade no comércio local, sendo assim foram realizadas quatro coletas, incluindo lotes de arroz polido (6 marcas), parboilizado e integral (4 marcas cada). Conforme o mencionado de cada coleta foram formadas amostras analiticas de cada marca, compostas por $1 \%$ dos pacotes de $1 \mathrm{~kg}$ disponiveis nas prateleiras dos estabelecimentos comerciais amostrados.

As amostras foram tomadas ao acaso e sua representatividade no que diz respeito, à quantidade coleta$\mathrm{da}$, foi adequada considerando-se que a quantidade de pacotes de mesma marca nas prateleiras dos supermercados foi relativamente pequena e a amostra bruta conseqüentemente ultrapassava o valor de $1 \%$ estipulado para a coleta.

A alta rotatividade das marcas e conseqüente ausência na prateleira fez com que nem todas as marcas fossem coletadas no mesmo momento, porém com o cuidado para que estivesse no período de validade e sempre que disponiveis em diferentes períodos do ano.

\section{2 - Avaliação da ocorrência de micotoxinas}

As técnicas de cromatografia de camada delgada usadas apresentavam os seguintes limites de detecção: para as aflatoxinas $2,5 \mu \mathrm{g} / \mathrm{kg}$; para ocratoxina A $6,0 \mu \mathrm{g} /$ $\mathrm{kg}$ e $45 \mu \mathrm{g} / \mathrm{kg}$; para DON $120 \mu \mathrm{g} / \mathrm{kg}$ e para toxina T2 $138 \mu \mathrm{g} / \mathrm{kg}$. Nestes os niveis de recuperação das toxinas naturalmente fluorescentes apresentaram valores entre 90 e $97 \%$, enquanto que as toxinas que necessitavam de revelação para visualização tiveram seus niveis variando entre $78,80,5$ e $90 \%$ respectivamente, para toxina T2, DON e zearalenona.

A Tabela 1 apresenta os resultados da triagem e quantificação das micotoxinas, aflatoxinas $\mathrm{B}_{1}, \mathrm{~B}_{2}, \mathrm{G}_{1}, \mathrm{G}_{2}$, ocratoxina $\mathrm{A}$, zearalenona, desoxinivalenol e toxina $\mathrm{T}-2$, determinadas pelos métodos que apresentavam os indicadores de performance acima relatados.

Os resultados mostraram que a micotoxina mais freqüentemente detectada foi a zearalenona, que foi confirmada em três amostras de diferentes marcas e coletas, sendo que em uma apareceu simultaneamente com a ocratoxina A. É importante salientar os niveis determinados foram considerados altos, pois são até vinte vezes maiores que os limite de detecção. $O$ fato levou a repetir as determinações e nos procedimentos de confirmação foi usada também a co-cromatografia além da derivação química.

Para esta toxina não foi ainda estabelecido limite de seus teores para a comercialização de arroz e seus derivados, destinados ao consumo humano, pois ela vem sendo pouco relatada neste tipo de amostras. No entanto, pode-se observar que esta toxina vem sendo encontrada com certa freqüência em cereais cultivados na região [4,12]. Fungos do gênero Fusarium são detectados na região Sul da América do Sul e a probabilidade de vir a encontrar condições bióticas e abióticas que propiciem o seu desenvolvimento em arroz com conseqüente produção de micotoxinas precisa ser melhor estudada [7, 19].

TABELA 1. Amostras de arroz suspeitas e contaminadas pelas técnicas de CCD.

\begin{tabular}{|c|c|c|c|}
\hline \multirow[t]{2}{*}{ Subgrupo } & Micotoxina & Amostras & Níveis Detectados \\
\hline & Suspeita & Confirmadas & $\left(\mu \mathrm{g} \cdot \mathrm{Kg}^{-1}\right)$ \\
\hline \multirow[t]{3}{*}{ Arroz Integral } & Aflatoxina $B_{1}(3)$ & $\mathrm{Nd}$ & - \\
\hline & Ocratoxina A (1) & $\mathrm{Nd}$ & - \\
\hline & Zearalenona (1) & $\mathrm{Nd}$ & - \\
\hline \multirow[t]{3}{*}{ Arroz Parboilizado } & Zearalenona (4) & 2 & 559 e 1955 \\
\hline & Ocratoxina A (2) & 1 & 128 \\
\hline & Toxina T-2 (1) & - & \\
\hline \multirow[t]{3}{*}{ Arroz Polido } & Zearalenona (4) & 1 & $1117^{*}$ \\
\hline & Ocratoxina A (1) & 1 & $104^{*}$ \\
\hline & Desoxinivalenol (1) & 1 & 266 \\
\hline
\end{tabular}

Nd: não detectado
${ }^{*}$ co-contaminação

Outro ponto observado, na Tabela 2, é que não foram identificados fungos do gênero Fusarium, produtores desta toxina, nas amostras estudadas. Possivelmente estes fungos tenham estado contaminando as amostras no campo e foram substituidos por outros gêneros mais adaptados as condições do armazenamento, porém a micotoxina permaneceu $[14,15]$.

O subgrupo de arroz mais afetado foi o parboilizado. A contaminação do arroz parboilizado poderia ser justificada pelo fato de que foi submetido a um encharcamento prévio ao descascamento, que poderia propiciar a migração de micotoxinas das camadas mais externas para o interior do grão, conforme foi demonstrado por COELHO et al [7].

O número de amostras com resultados falsos positivos reforça a necessidade de realizar os procedimentos 
de confirmação, como já vinha sendo preconizado por outros autores [4, 18].

Durante a determinação de DON e toxina T2 por cromatografia gasosa os tempos de retenção destas toxinas foram respectivamente 4,9 e 18,1 minutos, na coluna empregada. Com relação aos indicativos de performance do método descrito obteve-se $90 \%$ de recuperação para DON e limites de detecção de $10 \mu \mathrm{g} / \mathrm{Kg}$ para DON e $12,5 \mu \mathrm{g} / \mathrm{Kg}$ para toxina T2 e recuperação média de $89 \%$.

A triagem das amostras indicou 2 amostras suspeitas de contaminação por DON, no subgrupo do arroz polido. Uma destas foi a mesma detectada por cromatografia de camada delgada. Os teor encontrado numa amostra foi de $300 \mu \mathrm{g} / \mathrm{kg}$ e a outra não foi confirmada.

Este valor mais alto, em relação ao determinado por cromatografia de camada delgada, da mesma toxina e amostra, pode ser atribuido ao fato que este último é um método semi-quantitativo e com niveis de recuperação maior que o primeiro. Na Figura 1 aparece o perfil cromatográfico da amostra de arroz contaminada.

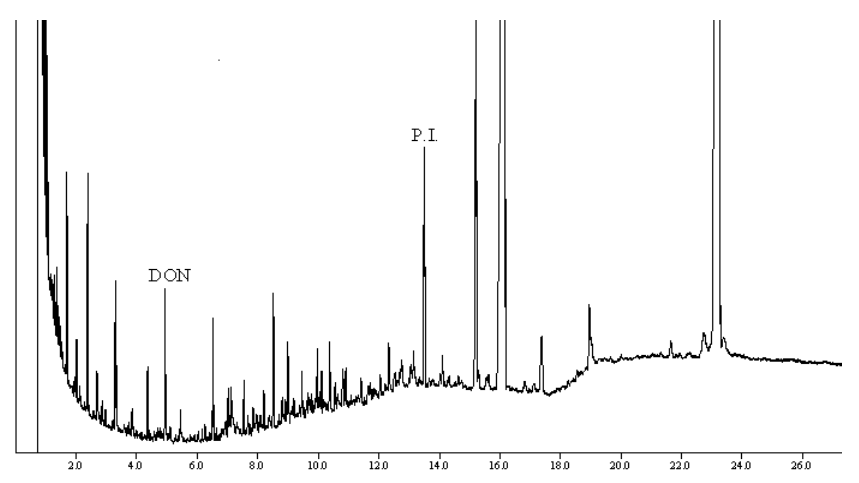

FIGURA 2. Perfil cromatográfico da amostra contaminada com DON.

\section{3 - Enumeração e identificação de bolores.}

Apenas 3,6\% das amostras analisadas apresentaram contagem de bolores e leveduras superior a $10^{4} \mathrm{UFC} / \mathrm{g}^{-1}$, além destas, $11 \%$ apresentaram valores próximos deste máximo de contaminação, indicado para outros cereais.

As amostras de arroz branco foram as que apresentaram as maiores variações nos niveis de UFC determinados (variando entre 30 e 1,9 x 10 $)$, estando neste grupo os valores mais altos. Em seguida estavam as amostras de arroz integral, grupo onde se encontram 7 amostras próximas ao limite máximo de 1 x $10^{4} \mathrm{UFC} / g$. No grupo de arroz parboilizado uma amostra apresentou 2,4 x 104 UFC/g. Na Figura 2 aparece um gráfico construído utilizando como $Y$ o log da raiz quadrada do número de UFC encontrado para as amostras correspondentes a cada subgrupo de arroz. Foi desta forma que se conseguiu diminuir a variação e observar o perfil da contaminação.

A legislação vigente do MINISTÉRIO DA AGRICULTURA [11] não estabelece limites de contaminação por fungos para o arroz, apenas refere que o produto que apresentar mau estado de conservação, incluindo processos de fermentação e mofo será desclassificado para consumo. Sendo assim o parâmetro utilizado para comparar o teor da contaminação foi o de outros tipos de cereais que também sofrem preparo industrial ou doméstico antes do consumo.

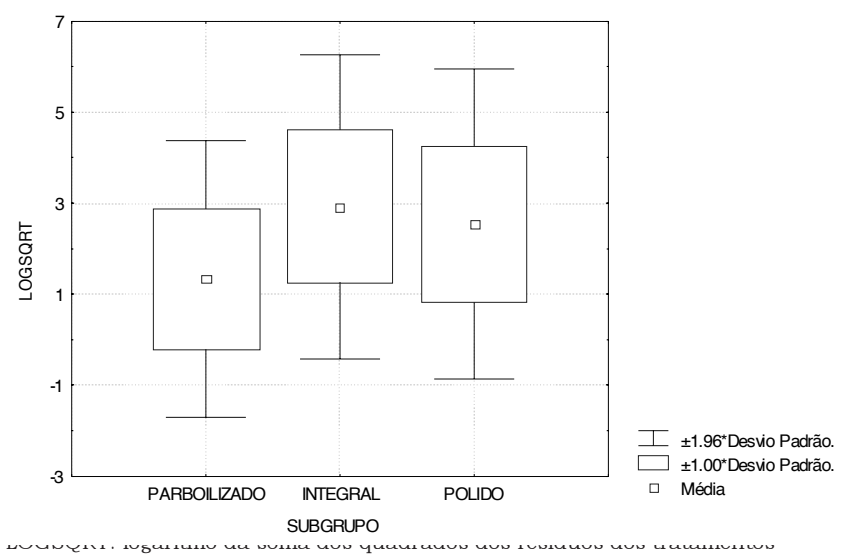

FIGURA 3. Perfil da contaminação por mofos e leveduras.

As colônias mais freqüentes foram isoladas e identificadas através das características macroscópicas de cor, diâmetro e aspecto e através das características microscópicas, comparando as mesmas com as descrições feitas por PITT \& HOCKING [14], SAMSON e HOEKSTRA [15]. A Tabela 2 apresenta os fungos contaminantes das amostras de arroz.

TABELA 2. Freqüência dos fungos contaminantes das amostras de arroz.

\begin{tabular}{llll}
\hline Fungo & Amostras infectadas & Subgrupo mais afetado \\
Aspergillus spp & 12 & Polido (6) \\
Aspergillus flavus & 4 & Polido (4) \\
Aspergillus parasiticus & 5 & Parboilizado (3) \\
Aspergillus terreus & 2 & Parboilizado (1), Polido (1) \\
Cladosporium spp & 1 & Polido (1) \\
Curvularia spp & 2 & Polido (1), Integral (1) \\
Penicillium spp & 15 & Polido (9) \\
Phoma spp & 3 & Polido (2) \\
Rhizopus spp & 1 & Polido (1)
\end{tabular}

Como pode ser observado na Tabela 2 os gêneros mais comuns foram Aspergillus e Penicillium. Estes gêneros fúngicos também foram descritos como principais contaminantes de arroz parboilizado e farelo de arroz por JAIARAMAN e KALYANASUNDARAM [8], sendo o Aspergillus flaurus a espécie de maior freqüência. BANDARA et al [5]; ALMEIDA et al. [2]; TONON et al. [19] e LIMA et al [10], também verificaram a ocorrência destes gêneros em estudos envolvendo a avaliação da micoflora em arroz e derivados e com menor freqüência Fusarium spp, Cladosporium spp, Curvularia spp, Phoma spp, Rhizopus $\mathrm{spp}$, coincidindo igualmente com os resultados obtidos. 


\section{4 - Identificação de sujidades}

A presença de sujidades nos alimentos pode ser um indicativo de descuidos com o controle higiênico-sanitário durante o processamento e armazenamento do produto. Insetos podem funcionar como veiculadores de contaminantes fúngicos. Por esta razão a microscopia vem sendo adotada como prática corrente na avaliação de qualidade de produtos alimentícios.

Do total de amostras analisadas em relação à presença de sujidades 9 amostras (5 de arroz integral, 1 parboilizado e 2 de polido) apresentaram sujidades tais como insetos, fragmentos de insetos e pedra. Foram encontrados no máximo 2 insetos e 3 fragmentos em uma mesma amostra. Coube a exceção a uma amostra de arroz integral tipo 1 que apresentou maior quantidade de insetos vivos, que ultrapassaram $0,25 \%$ de matéria estranha .

A legislação vigente do Ministério da Agricultura permite que o arroz em casca tenha no máximo $2 \%$ em peso de matéria estranha. O percentual de matéria estranha e impurezas permitido para o arroz beneficiado diferem entre os subgrupos e tipos de arroz. O arroz integral e o arroz polido tipo 1 podem conter $0,25 \%$ de matéria estranha e impurezas e o tipo 2 0,5\%.

\section{4 - CONCLUSÕES}

- A zearalenona foi a micotoxina mais freqüente nas amostras estudadas, em niveis bastante elevados (559, 1117 e $\left.1955 \mu \mathrm{g} \cdot \mathrm{kg}^{-1}\right)$, seguida pela ocratoxina A

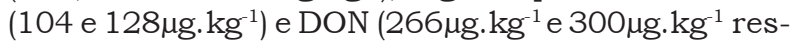
pectivamente por $\mathrm{CCD}$ e $\mathrm{CG})$.

- A enumeração de bolores e leveduras, mostrou que $3,6 \%$ das amostras apresentaram niveis superiores a $10^{4} \mathrm{UFC} \mathrm{g}^{-1}$ e $11 \%$ estavam muito próximos a este valor. Em todos os casos os fungos mais freqüentes pertenciam aos gêneros Penicillium e Aspergillus.

- As marcas e subgrupos analisados quando suas sujidades microscópicas mostraram que apenas uma amostra de arroz integral não se adequava aos limites do Ministério da Agricultura para este tipo de grão [11].

- Os resultados sugerem a necessidade de se realizar um monitoramento destes produtos para a ocorrência destas micotoxinas, visando um posterior estabelecimento de uma legislação específica .

\section{5 - REFERÊNCIAS}

[1] AGRIANUAL - FNP Consultoria e Comércio, 161-171, 1999.

[2] ALMEIDA, R.M. A. Mycoflora and Aflatoxigenic Species of Aspergillus spp isolated from rice. Revista de Microbiologia, v.22, n.2, p.161-163, 1991.

[3] A.O.A.C. INTERNATIONAL. Official Methods of Analysis of International Chemistry Society. $16^{\text {th }}$ Edition, Arlington, Virginia - USA, 1995
[4] BADIALE-FURLONG, E., SOUZA SOARES, L. A, DADALT, G. Aflatoxinas, Ocratoxina A e Zearalenona em Alimentos da Região Sul do Rio Grande do Sul. Revista do Instituto Adolfo Lutz, v.58, n.2, p.105-111, 1999.

[5] BANDARA, J. M. R. S., VITHANEGE, A. K., BEAN, G. A. Ocurrence of aflatoxins in parboiled rice in Sri Lanka. Mycopatologia, n.116, p. 65-70, 1991.

[6] BARAJ, E. Interferência de Tricotecenos Nos Processos Fermentativos. (Dissertação de Mestrado em Engenharia de Alimentos), Fundação Universidade Federal do Rio Grande, Rio Grande, RS, 2000.

[7] COELHO, C. S. P., BADIALE-FURLONG, E. , ALMEIDA, T.L. Migração de Micotoxinas durante a parboilização do Arroz. Brazilian Journal of Food Technology, v(1,2), p. 39-44, 1999.

[8] JAIARAMAN, P. , KALYANASUNDARAM, I. Natural ocurrence of Toxigenic Fungi and Mycotoxins in Rice Bran. Mycopatology, n. 110, p. 81-85, 1990.

[9] KIESSLING, K. H. Biochemical mechanism of action of mycotoxins. Pure \& Applied Chemistry, v.58, n.2, p. 327-338, 1986.

[10] LIMA, C. A. P.; ORSI, R. B.; DILKIN, P.; CORREAA, B. Mycoflora and aflatoxigenic in derivatives of milled rice. Ciênc. Tecnol. Aliment., v.20,n. 1, p.37-39, 2000.

[11] MINISTÉRIO DA AGRICULTURA. Portaria № 269 de 17 de novembro de 1988.

[12] NORDIN, N. S. D. Detecção de Aflatoxinas e Zearalenona em milho (Zea mays) destinado à alimentação animal. (Dissertação de Mestrado) Porto Alegre, RS, 1995, 97p. Faculdade de Agronomia, Universidade Federal do Rio Grande do Sul.

[13] OSBORNE, B. G. Mycotoxins and the Cereal Industry - A Review. Journal of Food Technology, v. 17, p.1-9, 1982.

[14] PITT, J. I. , HOCKING, A. D. Fungi and Food Spoilage. Blackie Academic \& Professional, 1997, 529p.

[15] SAMSON, R. A., REENEN-HOEKSTRA, E. S. Introdution to Food-Borne Fungi. Es. Centraalbureau Voor Schimmelcultures, 1998, 299p.

[16] SCHOLLENBERGER, M.; LAUBER, U.; JARA, H. T.; SUCHI, S.; DROCHNER, W.; MULLER, H. M. Determination of eight trichothecenes by chromatography - mass spectrometry after sample clean-up by a two-stage solid-phase extraction. Journal Chromatography A, v.815, p.123-132, 1998.

[17] SILVA, N. , JUNQUEIRA, V. C. A., SILVEIRA, N. F. A. Manual de Métodos de Análise Microbiológica de Alimentos. São Paulo, Varela, 1997, 295p.

[18] SOARES, L. M. V. Micotoxinas: Um método para análise simultânea e incidência em alimentos comercializados na região de Campinas, SP (tese de doutorado) FEA UNICAMP, 1987.

[19] TONON, S. A.; MARUCCI, R. S.; JERKE, G.; GARCIA, A. Mycoflora of paddy and milled rice produced in the region of Northeastern Argentina and Southern Paraguay. International Journal of Food Microbiology v.3, p.231235, 1997.

[20] VIEIRA, N.R. ${ }^{\text {, }}$ CARVALHO, J. L. V. Qualidade Tecnológica do Arroz. In: Vieira, N.R. A., SANTOS, A. B., SANT'ANA, E. P. A. Cultura de Arroz no Brasil. Embrapa Arroz e Feijão: Goiás, 1999. 633p.

\section{6 - AGRADECIMENTOS}

\section{CAPES e FAPERGS pelo auxilio financeiro}

